\title{
PACHYTENE CHROMOSOME MORPHOLOGY AT DIFFERENT PLOIDY LEVELS IN MEDICAGO
}

\author{
C. B. GILLIES and K. LESINS \\ Department of Genetics, University of Alberta, Edmonton, Alberta, Canada
}

Received 1.xii.70

\section{InTRODUCtION}

Differences in somatic chromosome size between homologous chromosomes of closely related plant species at different levels of ploidy have been noted by several workers (Manton, 1950; Pegington and Rees, 1970). Indications that this phenomenon occurred in pachytene chromosomes came from a report that the pachytene chromosomes of commercial alfalfa (Medicago sativa), a terraploid, were considerably shorter than those of diploid $M$. sativa (Gillies, 1968, 1970b). The availability of diploid, autotetraploid and essentially autohexaploid plants of $M$. sativa and $M$. falcata have made possible the comparison of pachytene chromosomes at three ploidy levels. $M$. falcata is cytologically and genetically almost indistinguishable from $M$. sativa, and the two will be referred to under the name M. sativa sensu lato (s.l.) (Lesins, 1961 ; Gillies, 1970a).

\section{MATERIALS AND Methods}

The diploid used was a plant of $M$. falcata L. (U. of A. Accession No. 136), and the tetraploid was derived from it by colchicine treatment (autotetraploid 1-5-2). The nexploid (hexa 8-13) was obtained by a backcross of a colchicine induced auto-octaploid to the parental tetraploid $M$. sativa, a commercial cultivar. Pachytene stage cells of each were prepared from pollen mother cells by the same technique (Gillies, 1968), and chromosomes were measured from photographs at the same magnification. The chromosomes were classified into eight classes of a common haploid idiogram (fig. 1), and mean lengths and arm ratios were calculated for each chromosome class at each ploidy level.

\section{Results AND Discussion}

As only a limited number of measurements were available for some hexaploid chromosome classes, only four chromosomes will be considered here, chromosomes 3, 4, 6 and 7. The first two are asymmetrical submetacentrics, the latter two are symmetrical metacentrics (centromere positions classified according to nomenclature of Levan, Fredga and Sandberg (1964). The data for these four are given in table 1. Chromosomes 3 and 6 of the three ploidy levels are shown in figs. 2-7 of Plate I.

$\mathrm{F}$ tests were carried out to determine if there were significant effects of ploidy on chromosome length and arm ratio. In all four chromosome classes there were highly significant effects of ploidy on length. It can be seen from table 1 that the reductions in length from diploid to tetraploid are much greater than the reductions from tetraploid to hexaploid. In all four chromosomes the diploid-tetraploid length differences were significant, 
3

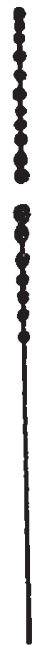

5

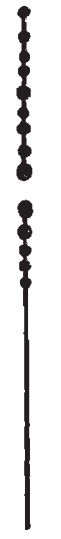

6

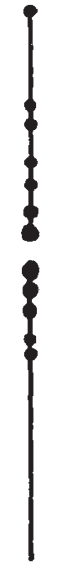

7

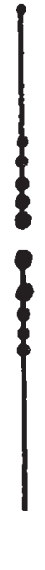

8

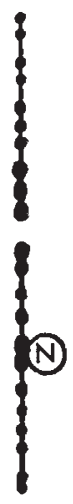

Frg. 1.-Haploid idiogram of pachytene chromosomes of $M$. sativa s.l. showing proportional lengths, arm ratios and positions of major chromomeres. $\mathrm{N}$ is the position of the nucleolus. Numbered according to the order of the idiogram agreed to for M. sativa L. by the 22nd National Alfalfa Improvement Conference, at the University of Illinois, 12-15th July 1970.

TABLE 1

Comparison of mean lengths and arm ratios of diploid, tetraploid and hexaploid Medicago pachytene chromosomes

\begin{tabular}{|c|c|c|c|c|c|c|c|c|}
\hline Chr & mosome & & Mean values & & & Signi & differ & nce $\ddagger$ \\
\hline No. & Item $\dagger$ & $2 n(a)$ & $4 n(b)$ & $6 n(c)$ & value & $a-b$ & $a-c$ & $b-c$ \\
\hline 3 & $\left\{\begin{array}{l}\mathbf{L} \\
\mathrm{AR} \\
\mathrm{N}\end{array}\right.$ & $\begin{array}{c}36 \cdot 1 \pm 0.81 \\
2 \cdot 82 \pm 0 \cdot 138 \\
21\end{array}$ & $\begin{array}{c}25 \cdot 3 \pm 0 \cdot 89 \\
2 \cdot 26 \pm 0 \cdot 204 \\
7\end{array}$ & $\begin{array}{c}21 \cdot 0 \pm 0 \cdot 55 \\
2 \cdot 00 \pm 0 \cdot 117 \\
8\end{array}$ & $\begin{array}{r}51 \cdot 96 * * \\
7 \cdot 18 * *\end{array}$ & $\begin{array}{l}X \\
X\end{array}$ & $\begin{array}{l}\mathrm{X} \\
\mathrm{X}\end{array}$ & $\begin{array}{c}\mathrm{X} \\
\text { n.s. }\end{array}$ \\
\hline 4 & $\left\{\begin{array}{l}\mathrm{L} \\
\mathrm{AR} \\
\mathrm{N}\end{array}\right.$ & $\begin{array}{c}31 \cdot 1 \pm 0.82 \\
2 \cdot 55 \pm 0 \cdot 090 \\
17\end{array}$ & $\begin{array}{c}20 \cdot 6 \pm 0 \cdot 71 \\
2 \cdot 07 \pm 0 \cdot 176 \\
5\end{array}$ & $\begin{array}{c}19 \cdot 3 \pm 0.68 \\
1.80 \pm 0.179 \\
6\end{array}$ & $\begin{array}{r}51 \cdot 10^{* *} * \\
9 \cdot 25 * *\end{array}$ & $\begin{array}{l}X \\
X\end{array}$ & $\begin{array}{l}\mathrm{X} \\
\mathrm{X}\end{array}$ & $\begin{array}{l}\text { n.s. } \\
\text { n.s. }\end{array}$ \\
\hline 6 & $\left\{\begin{array}{l}\mathrm{L} \\
\mathrm{AR} \\
\mathrm{N}\end{array}\right.$ & $\begin{array}{c}30.8 \pm 0.71 \\
1.36 \pm 0.076 \\
19\end{array}$ & $\begin{array}{c}21 \cdot 6 \pm 0 \cdot 27 \\
1 \cdot 26 \pm 0 \cdot 101 \\
10\end{array}$ & $\begin{array}{c}18.6 \pm 0.69 \\
1 \cdot 15 \pm 0.091 \\
10\end{array}$ & $\begin{array}{c}96 \cdot 13 * * \\
1.53\end{array}$ & $\begin{array}{c}\mathrm{X} \\
\text { n.s. }\end{array}$ & $\begin{array}{c}\mathrm{X} \\
\text { n.s. }\end{array}$ & $\begin{array}{c}\mathrm{X} \\
\text { n.s. }\end{array}$ \\
\hline 7 & $\left\{\begin{array}{l}\mathrm{L} \\
\mathrm{AR} \\
\mathrm{N}\end{array}\right.$ & $\begin{array}{c}27.3 \pm 0.87 \\
1.07 \pm 0 \cdot 048 \\
15\end{array}$ & $\begin{array}{c}19 \cdot 2 \pm 0.48 \\
1 \cdot 12 \pm 0 \cdot 092 \\
8\end{array}$ & $\begin{array}{c}17 \cdot 1 \pm 0 \cdot 44 \\
1 \cdot 15 \pm 0 \cdot 052 \\
8\end{array}$ & $\begin{array}{c}51 \cdot 75^{* *} \\
0.52\end{array}$ & $\begin{array}{l}\mathrm{X} \\
\text { n.s. }\end{array}$ & $\begin{array}{c}\mathrm{X} \\
\mathrm{n} . \mathrm{s} .\end{array}$ & $\begin{array}{l}\text { n.s. } \\
\text { n.s. }\end{array}$ \\
\hline
\end{tabular}


but only two chromosomes ( 3 and 6 ) had significant differences between tetraploid and hexaploid lengths in calculations using Duncan's multiplerange method (table 1 ).

The arm ratio decreases (table 1) from diploid to tetraploid were significant in chromosomes 3 and 4 , but decreases from tetraploid to hexploid in these chromosomes were non-significant. The $F$ values for arm ratio changes in chromosomes 6 and 7 were not significant.

Differences in contraction of chromosomes appear to be the immediate cause of the reduction in chromosome lengths with increase in ploidy level. The chromosomes were still identifiable by means of relative lengths, arm ratios and chromomere patterns. The more chromatic nature of the higher ploidy level chromosomes could be a result of the greater staining ability of the chromosomes as the DNA-histone complex of the chromosome becomes more compact. The chromosome lengths of the autotetraploid $M$. falcata reported here are very similar to those found in natural tetraploid $M$. sativa-26 to 18 microns (Gillies, 1970b). However Ho (1969) has found a diploid $M$. sativa with pachytene chromosomes ranging from 24 to 16 microns in length, and studies in this laboratory of other species closely related to $M$. sativa ( $M$. coerulea Less. and $M$. glandulosa David) have revealed diploids with pachytene chromosomes of a similar length to those of the tetraploids. This would suggest that pachytene chromosome length may be under genetic control. Thus it may be concluded that the length of pachytene chromosomes is under both ploidy and genetic control.

An extreme difference in behaviour of the arm ratios of the two submetacentrics ( 3 and 4 ) on the one hand, and the two metacentrics (6 and 7) on the other, is obvious. Chromosomes 3 and 4, which had significant arm ratio reductions, are the chromosomes with initially high arm ratios and highly chromatic short arms. It has been shown that in tomato pachytene chromosomes (which are similar in morphology to those of Medicago) the achromatic zones contract many more times than the chromatic ones (Brown, 1949; Ramanna and Prakken, 1967). It is reasonable therefore to expect the achromatic long arms of chromosomes 3 and 4 to contract more than the chromatic short arms, thus causing reductions in arm ratios. In the symmetrical, median centromered chromosomes 6 and 7 the contraction in both arms is more uniform and little change in arm ratios is to be expected due to contraction.

This was demonstrated by calculating the mean lengths of the long and short arms of chromosomes 3 and 7 at the three ploidy levels. Statistical tests showed that the decreases in the length of the long arm of chromosome 3 from diploid to tetraploid and tetraploid to hexaploid were both highly significant, whereas the short arm decreases were significant from diploid to tetraploid only. In chromosome 7 the decreases in the short arm length were both significant while the long arm decrease was significant from diploid to tetraploid but not from tetraploid to hexaploid.

The exact cause of the increased contraction of pachytene chromosomes at the higher ploidy levels is uncertain. Darlington (1964) states that polyploid species regularly have chromosomes smaller than their diploid relatives, probably as an evolutionary adaption to increases in chromosome number. Lewis and John (1963) discussed a number of cases of polyploidy in coccids and aphids in which tetraploids and diploids had the same amount of DNA per cell, and where the smaller chromosome size of the 


\section{Plate I}

Medicago sativa s.l. pachytene chromosomes with centromere positions arrowed. $\times 4000$. (Bar indicates 10 microns.)

Frg. 2.-. Chromosome 3 of diploid $M$. falcata.

FIG. 3.-Chromosome 6 of diploid M. falcata.

Fig. 4.-Quadrivalent of chromosome 3 from tetraploid $M$. falcata.

FIG. 5.-Chromosome 6 of tetraploid M. falcata.

FIG. 6.-Chromosome 3 of hexaploid $M$. sativa.

FIG. 7.-Quadrivalent of chromosome 6 from hexaploid M. sativa. 

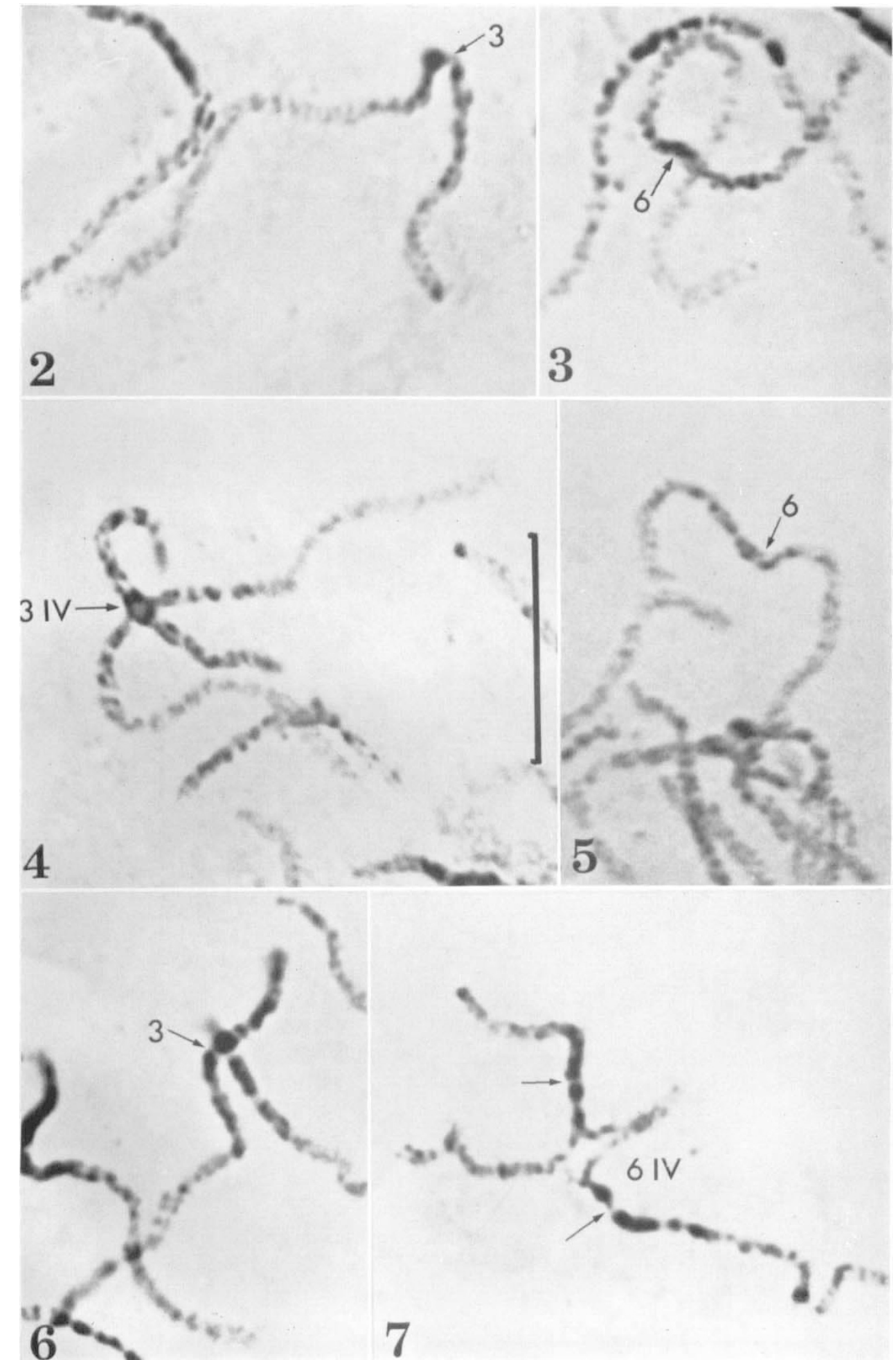
tetraploids was considered to be due to reduction in the level of chromosome polynemy. Martin (1968) concluded that the reduction in DNA value and size of chromosomes in Vicia was most likely similarly caused. Increases in ploidy level in Medicago may result in reduction in chromosome polynemy, but in view of the variations in the lengths of pachytene chromosomes in related diploid Medicago species mentioned above, it seems unlikely that differential polynemy is involved in this case.

It was suggested (Gillies, 1970b) that the shorter, more contracted chromosomes of natural tetraploid $M$. sativa might result either from a slightly later and hence more contracted stage of pachytene being more amenable to study in the tetraploid, or from contraction commencing earlier in the meiotic cycle of the tetraploid. Nuclear volumes of higher ploidy levels not being exact multiples of the nuclear volumes of diploid cells was suggested as a possible reason for the increased contraction. Ichikawa and Sparrow (1967) found nuclear volumes of tetraploid and hexaploid wheats were not as large as expected on the basis of diploid ancestors. However, Pegington and Rees (1970) found that nuclear dry mass and DNA at higher ploidy levels of wheat increased at exact multiples of the diploid values, and they concluded that the shorter somatic chromosomes in hexaploid wheat were due to increased metaphase coiling of the chromosomes which resulted in compaction. The reduction in pachytene chromosome lengths of Medicago sativa s.l. is clearly connected with contraction, but the exact reason for the ploidy effect on contraction is at present unknown.

\section{Summary}

1. Analysis of pachytene chromosomes of diploid, tetraploid and hexaploid Medicago sativa s.l. showed that there was a significant reduction in chromosome length with increase in ploidy level, the reducion from diploid to tetraploid being more pronounced than from tetraploid to hexaploid.

2. The length reduction appeared to be caused mainly by contraction of achromatic portions of chromosomes. In submetacentric chromosomes this resulted in a simultaneous reduction in arm ratio.

Acknowledgements.-We would like to thank Mr K.-M. Ho for allowing the use of unpublished thesis material. This study was supported by a Canadian Commonwealth Scholarship award to C. B. G., and by Canadian N.R.C. grant A-1425 to K. L.

\section{REFERENCES}

Brown, s. w. 1949. The structure and meiotic behaviour of the differentiated chromosomes of tomato. Genetics, 34, 437-461.

DARlington, C. D. 1964. Chromosome Botany and the Origins of Cultivated Plants. George Allen and Unwin, London.

GIllies, c. B. 1968. The pachytene chromosomes of a diploid Medicago sativa. Canad. 7 . Genet. Cytol., 10, 788-793.

Gillies, c. B. 1970a. Alfalfa chromosomes. I. Pachytene karyotype of a diploid Medicago falcata L. and its relationship to M. sativa L. Crop Sci., 10, 169-171.

Gillies, C. B. 1970b. Alfalfa chromosomes. II. Pachytene karyotype of a tetraploid Medicago sativa L. Crop Sci, , 10, 171-175.

но, к.-м. 1969. The pachytene chromosomes of diploid Medicago sativa L., diploid $M$. falcata L. and their hybrid. M.Sc. Thesis, University of Guelph. 
ICHIKAWA, S., AND SPARROW, A. H. 1967. Nuclear and interphase chromosome volumes of four Triticum species and of eight species from related genera. Wheat Inform. Serv. Kyoto Univ., 23-24, 18-20.

LESINS, K. 1961. Interspecific crosses involving alfalfa. I. Medicago dzhawakhetica (Bordz.) Vass. $\times$ M. sativa L. and its peculiarities. Canad. 7. Genet. Cytol., 3, 135-152.

LEVAN, A., FREDGA, K., AND SANDBERG, A. A. 1964. Nomenclature for centromeric position on chromosomes. Hereditas, 52, 201-220.

LEWIS, K. R., AND JoHN, B. 1963. Chromosome Marker. J. and A. Churchill, London.

manton, I. 1950. Problems of cytology and evolution in the Pteridophyta. Cambridge University Press, Cambridge.

MARTIN, P. G. 1968. Differences in chromosome size between related plant species. In Replication and Recombination of Genetic Material (Eds. W. F. Peacock and R. D. Brock), pp. 93-104. Aust. Acad. Sci., Canberra.

PEgInGton, C., AND REes, H. 1970. Chromosomal weights and measures in the Triticinae. Heredity, 25, 195-205.

RAMANNA, M. S., AND PRAKKEN, R. 1967. Structure of and homology between pachytene and somatic metaphase chromosomes of the tomato. 